\title{
A new species of Horismenus Walker (Hymenoptera, Eulophidae) from ootheca of Liturgusa Saussure (Mantodea, Liturgusidae) from Central Amazonas, Brazil
}

\author{
Christer Hansson ${ }^{1, \dagger}$, Diego G. Pádua ${ }^{2, \ddagger}$, Karine Schoeninger ${ }^{2, \S}$, \\ Antonio A. Agudelo ${ }^{2,1}$, Márcio L. Oliveira ${ }^{2, \pi}$
}

I Scientific Associate of the Natural History Museum, Cromwell Road, London SW7 5BD, United Kingdom 2 Programa de Pós-Graduação em Entomologia, Instituto Nacional de Pesquisas da Amazônia, André Araújo, 2936, CEP 96060, Manaus, Amazonas, Brasil

† http://zoobank.org/EC91EABD-7115-4B05-BC80-9195C86FA55D

† http://zoobank.org/62984359-999A-41DB-AFOE-6722EAD52DB9

§ http://zoobank.org/3B37E557-99CD-49BC-944F-8032B655216F

| http://zoobank.org/F7A9367B-9FE5-4198-8726-B067999B551A

II http://zoobank.org/32031B61-1FD0-416F-9AC1-8F7E5BC49072

Corresponding author: Christer Hansson (christerdennis@gmail.com)

Academic editor: S. Schmidt | Received 30 November 2013 | Accepted 2 February 2014 | Published 28 March 2014

http://zoobank.org/DACB1E82-CCBB-4839-B261-66B3EED290EF

Citation: Hansson C, Pádua DG, Schoeninger K, Agudelo AA, Oliveira ML (2014) A new species of Horismenus Walker (Hymenoptera, Eulophidae) from ootheca of Liturgusa Saussure (Mantodea, Liturgusidae) from Central Amazonas, Brazil. Journal of Hymenoptera Research 37: 53-60. doi: 10.3897/JHR.37.6729

\begin{abstract}
A new species of Horismenus Walker, H. liturgusae Hansson \& Schoeninger (Hymenoptera: Eulophidae), is described from material reared from an ootheca of an unidentified mantid species of genus Liturgusa Saussure (Mantodea: Liturgusidae). The new species is compared to H. argus Hansson, a species it is very similar to. Horismenus liturgusae sp. $\mathbf{n}$. is gregarious and 49 adult specimens developed in the ootheca. This is the first record of a Horismenus species parasitizing mantids, and the first record of a Horismenus species from an ootheca.
\end{abstract}

\section{Keywords}

Chalcidoidea, Entedoninae, parasitic wasp, gregarious parasitoid

Copyright Christer Hansson et al. This is an open access article distributed under the terms of the Creative Commons Attribution License (CC BY 4.0), which permits unrestricted use, distribution, and reproduction in any medium, provided the original author and source are credited. 


\section{Introduction}

Genus Horismenus Walker is one of the largest genera of the Eulophidae, Hansson (2009) included 400 species, which included all species known at that time. The genus has its main distribution in tropical America, but several species are also known from temperate North America. In addition two species have been recorded outside of the Americas, one from Europe (Bouček 1965) and one from India (Narendran et al. 2011). The species are parasitoids, developing either as primary or secondary parasitoids on a wide range of hosts. Hosts are known for $25 \%$ of the species and include immature insects from seven insect orders and several families, but also eggs (egg sacks) of four different families of spiders (Hansson 2009).

In Brazil species of Horismenus have been observed emerging from leafminer larvae (Phyllocnistis citrella Stainton) in citrus culture in the state of Acre (Thomazini and Albuquerque 2005), and as secondary parasitoids of the braconid Cotesia alius (Muesebeck) (Neto and Di Mare 2010). The record reported here, from ootheca of an unidentified species of Liturgusa Saussure, is the first record from the order Mantodea and also the first record from an ootheca.

The mantid genus Liturgusa (Fig. 13) is represented by 13 species in the Neotropics, of which eight are known from Brazil (Agudelo et al. 2007). It is the most common and widely distributed genus of the Liturgusidae. The species of this genus possess great agility and dexterity when moving, and also have an excellent camouflage, similar to lichens growing on tree trunks. Previously an unidentified Hymenoptera has been reared from oothecae of Liturgusa maya (Saussure \& Zehntner) (Ehrmann 2002).

\section{Material and methods}

\section{Photos}

The colour photos were made with Nikon SMZ1500 and Leica M165C stereomicroscopes and 5MP Nikon DS-L1 and DFC420 cameras respectively. Photos were taken at different focus levels, and Helicon Focus Pro version 4.75 and Leica Application Suite v3.4.1 (2009 version) were used to merge them into a single image. The SEM photos were made from uncoated specimens on their original cardboard mounting. These photos were taken in low vacuum mode on a Hitachi SU3500 scanning electron microscope.

\section{Abbreviations of morphological terms}

DE, distance between eyes, measured across the narrowest part on frons/vertex; DO, diameter of anterior ocellus; HE, height of eye in frontal view; HW, height of the forewing, measured across the widest part of the wing; $\mathbf{L C}$, length of median carina on propodeum, measured from anterior margin of carina to posterior margin of propodeum; LG, length of the gaster; LM, length of the marginal vein; LP, length of the petiole; $\mathbf{L S}$, length of 
hind tibial spur; $\mathbf{L T}$, length of hind tarsus; LW, length of the forewing, measured from the base of the marginal vein to the apical margin of the wing; MM, length of the mesosoma, measured along the median mesosoma, from the pronotal collar carina to posterior margin of the propodeum; MS, malar space; OOL, the distance between eye and posterior ocellus; PM, length of the postmarginal vein; POL, the distance between posterior ocelli; POO, the distance between posterior ocelli and occipital margin; ST, length of the stigmal vein; WC, width of the median carina on the propodeum, measured at equal distance from the anterior and posterior margins of the carina; WG, width of the submedian groove, measured at equal distance from the anterior and posterior margins of median propodeum; WH, width of the head, measured at widest part; WM, width of mouth opening; WP, width of the petiole, measured at the attachment point of the gaster; WT, width of the thorax, measured across the widest part which is usually just in front of the attachment point of the forewing, the "shoulders". For illustrations of the terms see Hansson (2009). Ratios given in the description are from female holotype and one male paratype.

\section{Acronyms}

BMNH the Natural History Museum, London, United Kingdom.

INPA Instituto Nacional de Pesquisas da Amazônia, Amazonas, Brazil.

\section{Rearing}

The conical-shaped ootheca (Fig. 14) was collected from a trunk of a Lecythis prance S.A. Mori (Lecythidaceae) at mid level, located in the grove Campus I of the Instituto Nacional de Pesquisas da Amazonia (INPA) and brought to the Laboratory of Hymenoptera, where the ootheca was stored in a glass container capped with fabric. After approximately three weeks 27 nymphs of Liturgusa emerged from the ootheca, and after one additional week 49 specimens of Horismenus liturgusae sp. n. emerged from the same ootheca. Furthermore, we found seven unhatched pupae of $H$. liturgusae within the ootheca. The mantid nymphs and the wasps emerged through the same single opening at the apex of the ootheca.

\section{Species description}

Horismenus liturgusae Hansson \& Schoeninger, sp. n. http://zoobank.org/73E0A73A-AADD-4660-B70C-1EAFB61FF4DA http://species-id.net/wiki/Horismenus_liturgusae

Figures 1-12

Diagnosis. Antennal scrobes joining below frontal suture (Figs 2, 3); mesoscutum with engraved reticulation (Fig. 5); scutellum smooth and shiny (Fig. 5); mesoscutum and scutellum metallic dark purple (Fig. 9); propodeal callus with three setae (Fig. 5); 


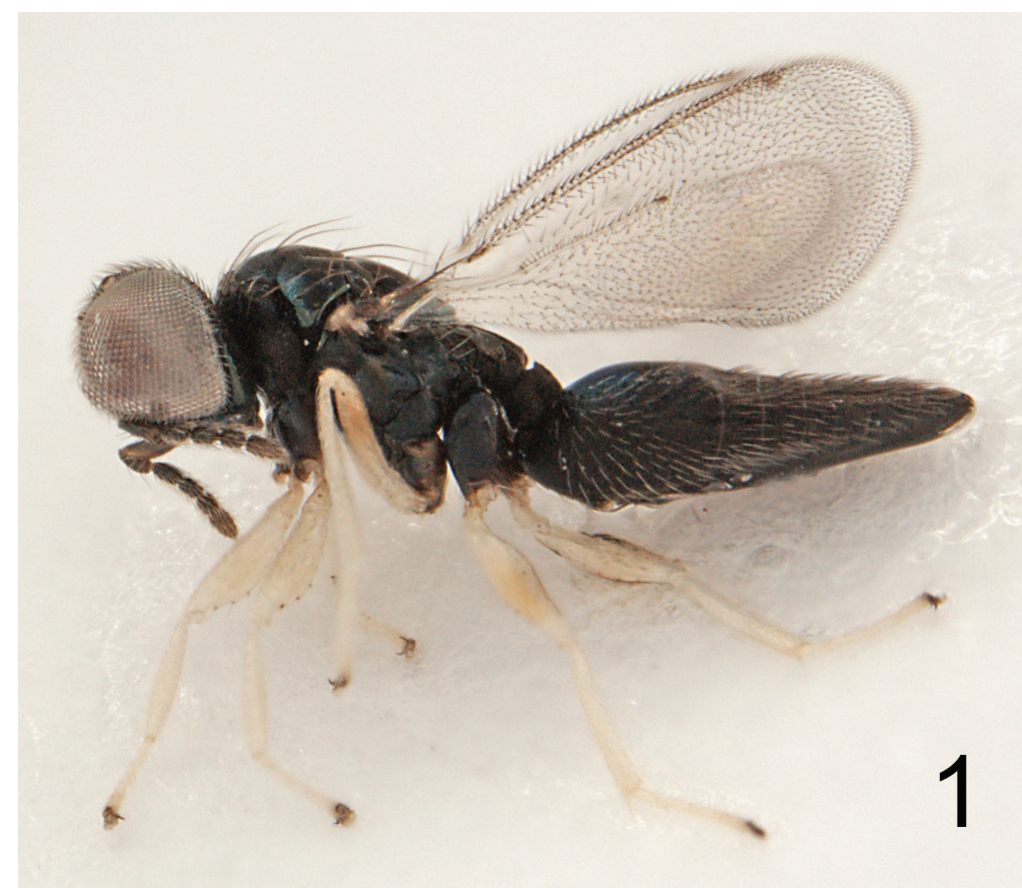

Figure I. Horismenus liturgusae sp. n. female, habitus, length of specimen $2.1 \mathrm{~mm}$.

femora and tibiae pale; eyes very large and frons very narrow (Figs 2-4, 7, 8), DE/ $\mathrm{DO}=1.4$ in female, 2.9 in male; gaster conspicuously hairy (Figs 6, 12). Similar to $H$. argus Hansson but with larger eyes in both sexes $(\mathrm{DE} / \mathrm{DO}=2.5$ in female, and $=3.3$ in male of $H$. argus), entire mesoscutum metallic dark purple (metallic bluish-green in $H$. argus) and with engraved reticulation throughout (sidelobes and anterior 1/2 of midlobe with raised and strong reticulation in $H$. argus), propodeal callus with three setae (two setae in $H$. argus), forewing costal cell with 2-5 setae on ventral side close to submarginal vein (costal cell bare in $H$. argus).

Description. FEMALE. Length 2.1-2.2 mm.

Entire antenna dark brown with metallic green tinges (Fig. 10). Frons metallic dark purple with parts close to eyes, part below level of toruli and part above frontal suture metallic bluish-green (Fig. 7). Vertex with anterior $1 / 2$ metallic bluish-green, posterior $1 / 2$ metallic dark purple. Mesoscutum, scutellum and propodeum metallic dark purple, mesoscutum with anterior margin metallic bluish-green (Fig. 9). Coxae metallic bluish-green; remaining parts of legs yellowish-white, mid and hind femora slightly infuscate (Fig. 1). Wings hyaline (Fig. 1). Petiole metallic dark purple. Gaster with first tergite with anterior $2 / 3$ metallic bluish-green, posterior $1 / 3$ metallic dark purple; remaining tergites metallic dark purple (Fig. 12).

Antenna as in Fig. 10. Frons below level of toruli, interscrobal area, areas along inner margin of eyes, and part just above frontal suture smooth and shiny, remaining parts with raised reticulation; frontal suture $\mathrm{V}$-shaped, incomplete, does not reach eyes; 


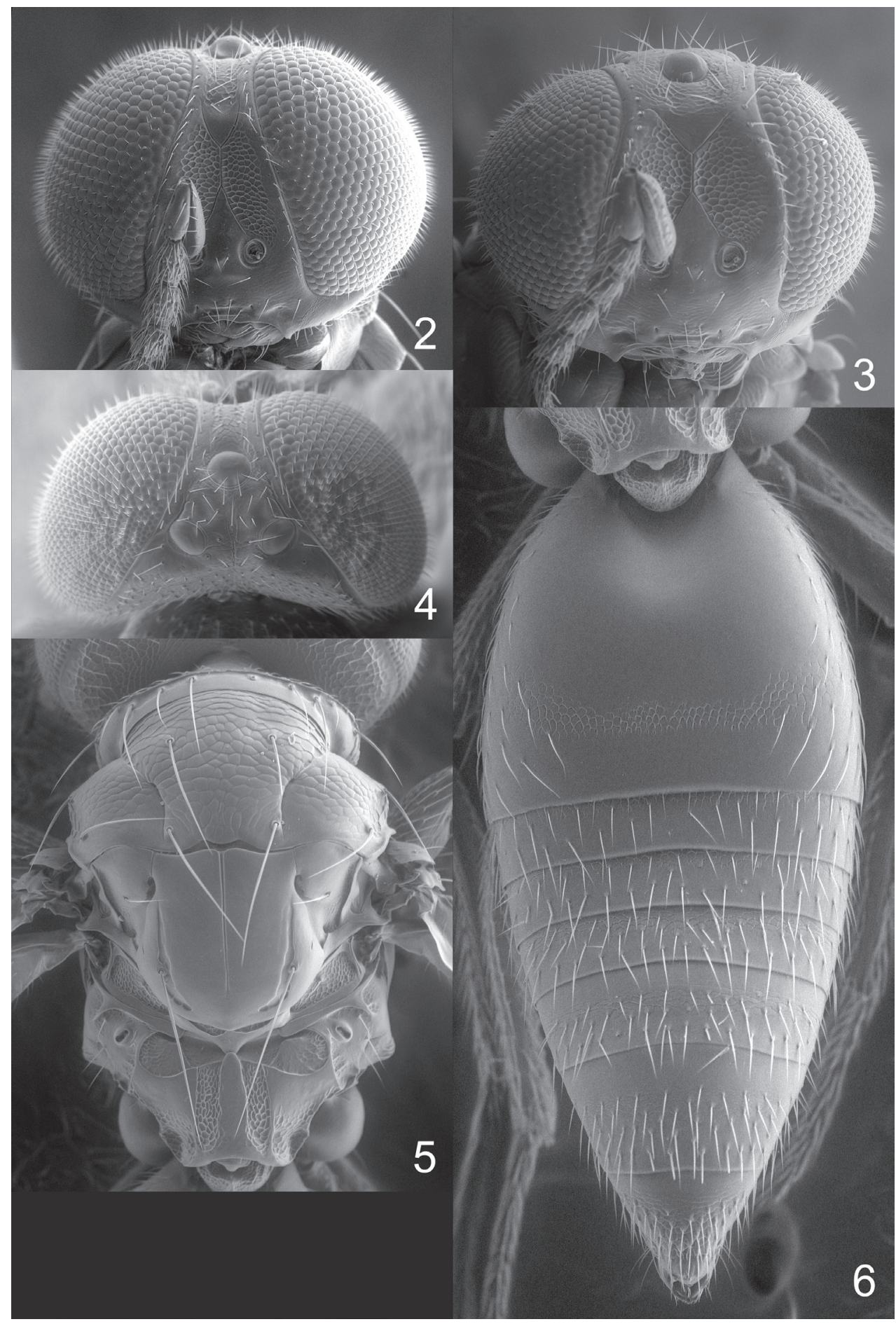

Figures 2-6. Horismenus liturgusae sp. n. 2 Head frontal, female 3 Head frontal, male 4 Vertex, female 5 Mesosoma dorsal, female 6 Gaster dorsal, female. 


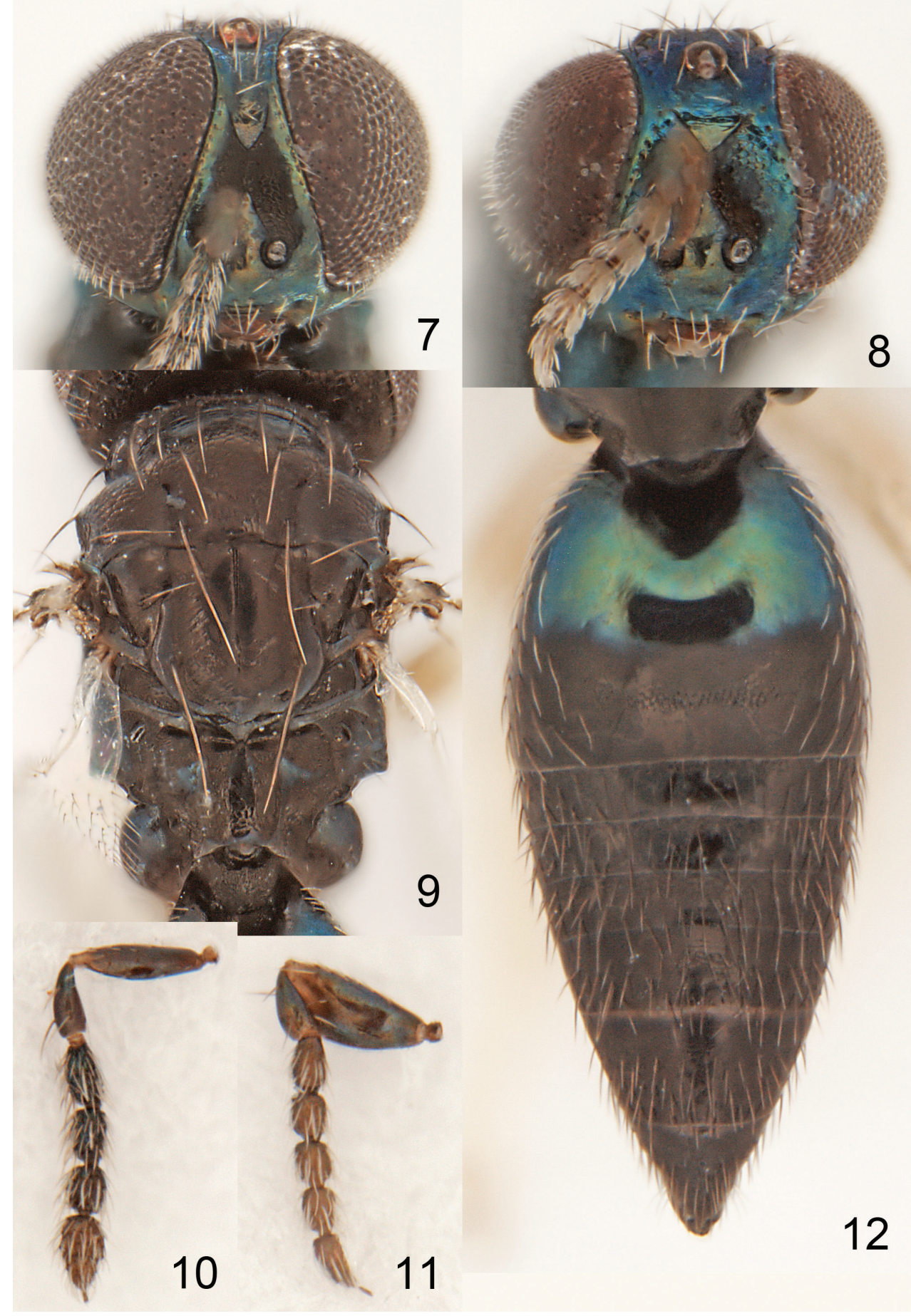

Figures 7-12. Horismenus liturgusae sp. n. 7 Head frontal, female 8 Head frontal, male 9 Mesosoma dorsal, female $\mathbf{0}$ Antenna lateral, female II Antenna lateral, male $\mathbf{2}$ Gaster dorsal, female. 


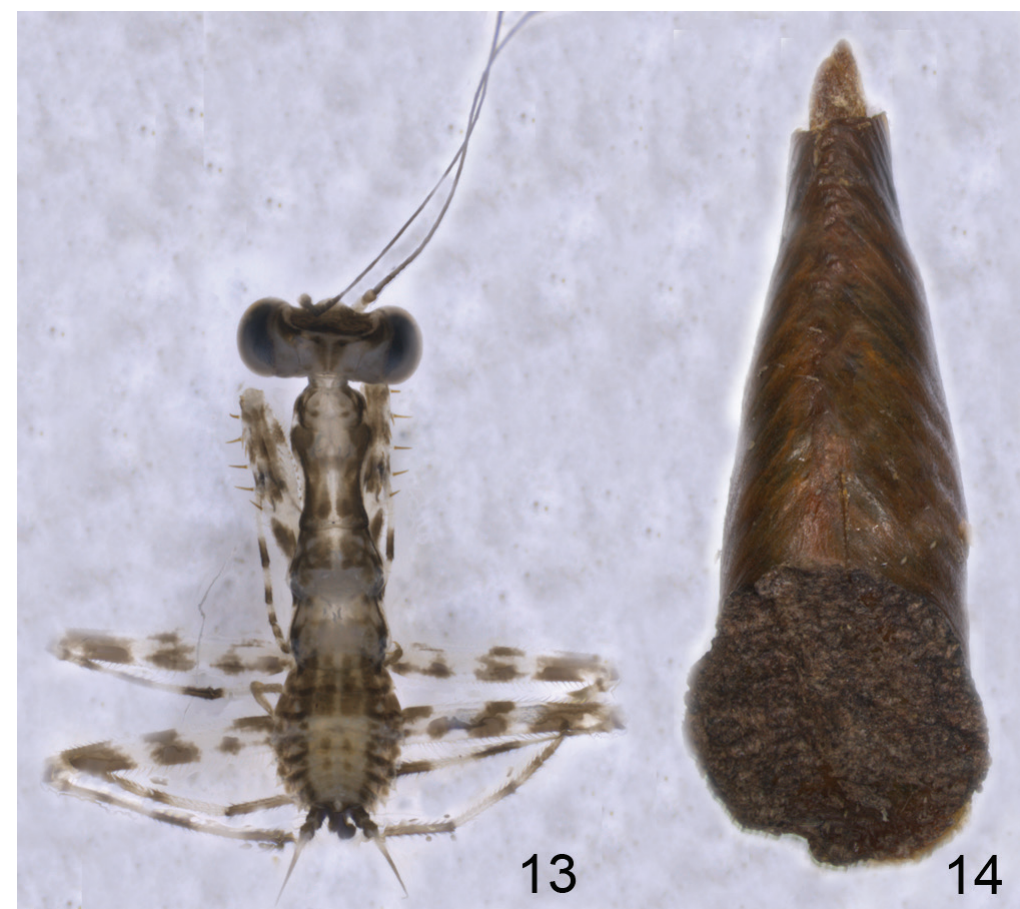

Figures I3-I4. Liturgusa sp. 13 Nymph, length $1 \mathrm{~mm} / 4$ Ootheca, length $10 \mathrm{~mm}$.

antennal scrobes joining below frontal suture (Fig. 2). Vertex with engraved and weak reticulation; posterior part with a median groove (Fig. 4). Occipital margin rounded (Fig. 4).

Mesoscutum with engraved reticulation; notauli narrow and distinct throughout (Fig. 5). Scutellum smooth and shiny (Fig. 5). Dorsellum convex and smooth, anterolaterally with two foveae (Fig. 5). Propodeum including median carina smooth and shiny, posterolateral propodeum and anterolateral foveae with weak reticulation, submedian grooves with strong reticulation (Fig. 5); propodeal callus with three setae. Coxae smooth and shiny. Forewing speculum closed below; with 23 admarginal setae; costal cell with 2-5 setae on ventral side close to submarginal vein.

Gaster with first tergite smooth with a reticulate band in posterior part (Fig. 6).

Ratios. DE/DO 1.4; WH/DE 6.5; HE/MS/WM 5.1/1.0/2.3; POL/OOL/POO 5.7/1.0/1.0; WH/WT 1.2; LW/LM/HW 1.8/1.3/1.0; PM/ST 1.0; LC/WC 3.5; WG/ WC 0.8; LS/LT 0.19; LP/WP 0.8; MM/LG 0.7-0.8.

Male. Length $1.7 \mathrm{~mm}$.

Similar to female except antenna (Fig. 11) with scape wider and with apical two flagellomeres separated.

Ratios. HE/MS/WM 4.4/1.0/2.3; LP/WP 1.2; MM/LG 1.5-1.6.

Distribution. Brazil.

Hosts. From ootheca of Liturgusa sp. (Mantodea: Liturgusidae). 
Material examined. Holotype female labeled "BRAZIL: Amazonas, Manaus, Campus I, 21.xi.2012, D.G. Pádua \& K. Schoeninger”, "Ex Liturgusa sp.” (INPA). Paratypes: 27 females and 22 males with same data as holotype (7f\# 6m\# in BMNH, $20 \mathrm{f} \# 16 \mathrm{~m} \#$ in INPA).

Etymology. Named after host.

\section{Acknowledgements}

Our thanks to the parataxonomist José Ferreira Ramos for the identification the specimen of Lecythidaceae and to Ola Gustafsson, Electron Microscopy Unit at the Department of Biology, Lund University, for help with the scanning electron microscope.

\section{References}

Agudelo AA, Lombardo F, Jantsch LJ (2007) Checklist of the Neotropical mantids (Insecta, Dictyoptera, Mantodea). Biota Colombiana 8(2): 105-158.

Bouček Z (1965) Studies of European Eulophidae, IV: Pediobius Walk. and two allied genera (Hymenoptera). Acta Entomologica Musei Nationalis Pragae 36: 5-90.

Ehrmann R (2002) Mantodea-Gottesanberinnen der Welt. Natur und Tier-Verlag, Münster, $519 \mathrm{pp}$.

Hansson C (2009) Eulophidae of Costa Rica, 3, the genus Horismenus. Memoirs of the American Entomological Institute 82: 1-916.

Narendran TC, Kumar PG, Kazmi SI (2011) A new record of the New World genus Horismenus Walker (Hymenoptera: Eulophidae: Entedoninae) from India with description of a new species. Journal of Environment and Sociobiology 8(2): 173-176.

Neto GS, Di Mare RA (2010) Hiperparasitoides em Cotesia alius (Mues.) (Hymenoptera: Braconidae) no estado do Rio Grande de Sul, Brasil. Magistra, Cruz das Almas-BA 22(3/4): 210-212.

Thomazini MJ, Albuquerque ES (2005) Ocorrência de Phyllocnistis citrella Stainton (Lepidoptera: Gracillariidae) em citros no estado do Acre, Brasil, 35(3): 395-398. 